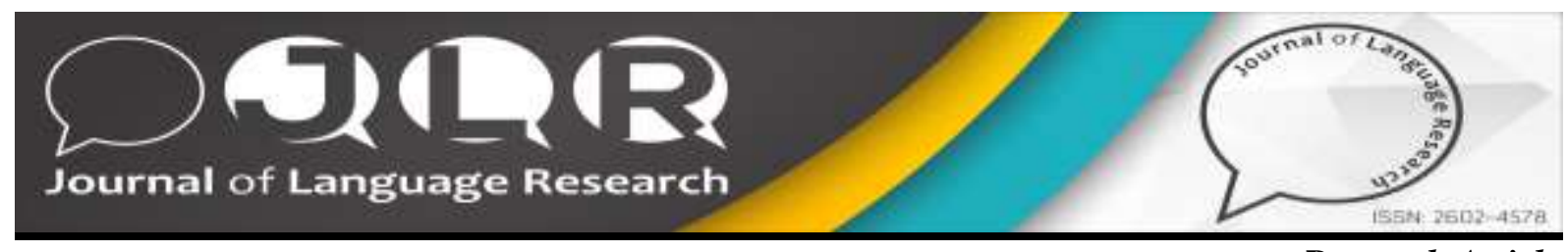

Research Article

\title{
Mind Matters: How is Mindset Correlated with Demographic Variables in Foreign Language Learning? ${ }^{1}$
}

\author{
İrem Altunel2 ${ }^{2}$, Gazi University, Instructor of English,iremaltunel@gazi.edu.tr
}

Recommended citation: Altunel, İ. (2020). Mind Matters: How is Mindset Correlated with Demographic Variables in Foreign Language Learning? Journal of Language Research (JLR) 4(1), 27-40.

\begin{abstract}
This study aimed to investigate the correlation between mindset and personal variables of EFL learners at both a private and a state university in Turkey. Quantitative methods were used, and Dweck's Mindset Instrument (DMI), which is a Likert-type scale, was administered to collect a set of data. Three demographic factors; namely gender, the program enrolled, and L2 proficiency level were used as variables. The study was conducted at the Preparatory School of Gazi University and Atılim University, with 203 participants. The data obtained from the scale were analyzed through both descriptive and inferential statistics using SPSS Statistics 21.0. Quantitative methods were used, and Dweck's Mindset Instrument (DMI) was administered to collect data. Findings revealed that male participants tended to have a more fixed mindset than female participants. However, no correlation was found between mindset and participants' program enrolled. Likewise, it was discovered that mindset and L2 proficiency level of participants were not correlated with each other.
\end{abstract}

Keywords: mindset, foreign language learning, demographic variables, correlation, quantitative

\section{INTRODUCTION}

A strong predictor of language achievement is the mindset that learners adopt, fixed vs. growth mindset, a famous and broadly embraced concept suggested by Dweck (2007). According to her, students who carry fixed mindset view the source of intelligence to be a virtue we are born with, stable and unchangeable whereas those with a growth mindset believe that intelligence is malleable, changeable and can be improved with persistence. Fairly limited empirical research has been carried out in this particular issue. In 2008, a research was conducted by Dweck to explore the achievement relevance between mindset and maths/science. The correlation between gender and mindset (Kornilova et al., 2009; Macnamara and Rupani, 2017; Spinath, Spinath and Riemann, 2003; Yan et al., 2014) and between mindset and academic achievement (Castella et al., 2015; Yeager et al., 2014) has also been explored in a few studies.

The ultimate goal of the current study is the determination of any existing connection of mindset and demographic variables of EFL learners studying at university in Turkey. Demographic variables in this study are gender, the program enrolled, and L2 proficiency level.

This research seeks to investigate the following research questions:

1. How does learners' gender correlate with their particular mindset?

2. Is there a statistically significant correlation between participants' enrolled program and their particular mindset?

3. What relationship exists between participants' L2 proficiency level and their particular mindset?

\footnotetext{
${ }^{1}$ This article has been produced from the author's Master's Thesis.

${ }^{2}$ ORCID: 0000-0001-6789-0587

Submitted: 18.05 .2020

Accepted: 30.08 .2020
} 
Mind Matters: How is Mindset Correlated with Demographic Variables in Foreign Language Learning?

\section{THEORETICAL FRAMEWORK}

Learners' beliefs about themselves and their own intelligences powerfully influence their learning success as these beliefs about the nature of intelligence structure their inferences, judgments, and reactions to different actions. A person's beliefs about the malleability, in other words, processability of intelligence are accepted as implicit theories of intelligence. Two implicit theories of intelligence have been identified by Dweck (2008): 'Incremental' and 'Entity'. To start with, entity theorists are of the opinion that intelligence is a fixed and stable trait, and people are born with it. Moreover, entity theorists believe that even though people are able to learn new information, their intelligence does not improve further (Ablard and Mills, 1996; Dweck, Chiu and Hong, 1995), and they are inclined to blame their own intelligence and abilities when they face failures. Consequently, they are at risk for academic underachievement since they do not tend to attempt challenging tasks and are more interested in seeming competent rather than learning new skills (Ablard and Mills, 1996) as they have "a high desire to prove themselves to others and to be seen as smart and avoid looking unintelligent" (2008, p. 1). Furthermore, they tend to orient more towards performance goals so that they can show their capability (Dweck, 2000).

On the other hand, learners with an "incremental" theory believe that their intelligence is malleable, changeable, and can be cultivated through effort and persistence. Moreover, they feel smart and comfortable by "engaging fully with new tasks, exerting effort to master something, stretching their skills, and putting their knowledge to good use." (Dweck, 2000). They want to challenge themselves to increase their abilities even if they fail at first. Moreover, as opposed to entity theorists, incremental theorists are more inclined to set learning goals for themselves rather than performance goals. While challenge is threatening for entity theorists, incremental theorists view it as informative even if these challenges cause them to make more mistakes while they are learning.

A great deal of research has been conducted to identify possible existence of various correlations between implicit theories of intelligence and learners' academic achievement. The findings of these studies reveal that there is indeed a correlation between them. One of these studies has been conducted by Elliot and Dweck (2005), proving that there is a correlation between implicit theories and academic achievement in that students' thoughts about intelligence and its malleability play a crucial role on both their academic achievement and how they learn.

In two studies (Bandura and Dweck, 1985; Dweck and Leggett, 1988), fifth, sixth and eighth grade students' theories of intelligence were measured by giving them some agreement and disagreement statements as follows:

"Your intelligence is something about you that you can't change very much."

"You can learn new things but you can't really change your basic intelligence."

"You have a certain amount of intelligence and you can't really do much to change it."

After a while, some certain tasks were given to students and they were told to choose any task they wish to work on. The first two tasks offered a performance goal whereas the third one offered a learning goal. The important point here was whether students holding different theories of intelligence would choose different goals to pursue. As a result, a significant relationship was found between students' theories of intelligence and the goals they pick. The findings showed that entity theorists tended to choose a performance goal while incremental theorists tended to choose a learning goal.

Carol Dweck (2007), the most important originator of the implicit theories of intelligence concept, also popularized the terms 'fixed' and 'growth' mindset. In the present context, what mindset refers to must be understood well since it is often quoted interchangeably with implicit theories of intelligence as a more popularized and recent terminology.

\section{Mindset}

Not all the learners are the same and their beliefs, behaviors, needs and skills highly differ from each other. However, there is one more point which is not all the same in learners: their mindset. Mindset 
İrem Altunel

refers to implicit beliefs about the malleability of personal attributes (Dweck, 2000). Based upon research studies regarding implicit theories of intelligence, achievement and success, Dweck (2006) has come up with a new concept named 'mindset', which makes all the difference in learning and teaching. This new and broadly embraced idea suggests that one can possess one of these two mindsets: fixed mindset or growth mindset. More specifically, Mercer (2012) asserts that the mindset in foreign language education "reflects the extent to which a person believes that language learning ability is dependent on some immutable, innate talent or is the result of controllable factors such as effort and conscious hard work." (p.22).

Those who carry a fixed mindset - entity theorists - support that the possessed intelligence level is stable and unable to change since it is an innate ability. According to Dweck:

In a fixed mindset, people believe their basic qualities, like their intelligence or talent, are simply fixed traits. They spend their time documenting their intelligence or talent instead of developing them. They also believe that talent alone creates success-without effort. They're wrong. (2016, p.1)

In other words, in a fixed mindset, students do not believe that they can indeed change and improve their existing intelligence since they view it as a stable and inborn quality. It is also worth mentioning that students avoid challenges or opportunities to learn if they feel that they may make mistakes (Mueller and Dweck, 1998, cited in Dweck, 2008). If they make mistakes or do something wrong, instead of correcting them, they tend to hide it (Nussbaum and Dweck, 2008) because they can easily give up when they face challenges and obstacles. Moreover, they are apt to ignore useful feedback, or even can take it personally. Since they do not believe that they become successful as long as they put enough effort, they do not use the feedback to learn, either. Rather, they believe that the higher innate ability they have, the more successful they will be. For this reason, they are afraid of failures as it means constraints or limits that they cannot readily overcome. Furthermore, if they witness the success of their peers, they may feel threatened rather than admiring.

In addition to what Dweck suggested about intelligence, Cattel's (1963) fluid and crystallized theory is also worth mentioning when it comes to intelligence. Raymond Cattell (1963), who was an influential psychologist, first came up with the concepts of fluid and crystallized intelligence, and he developed his theory with one of his students, John Horn, afterwards. The Cattell-Horn theory of fluid and crystallized intelligence introduced the idea that various abilities" interaction and working together produce the actual individual intelligence. According to this theory, fluid intelligence is defined as "the ability to perceive relationships independent of previous specific practice or instruction concerning those relationships." (Cattel, 1963). This type of intelligence is concerned with the ability to think abstractly and solve problems. Fluid intelligence does not depend on people's previous knowledge or experience. To clarify, solving a puzzle can be given as an example for the use fluid intelligence in that a person who cannot solve a puzzle with his/her existing knowledge will use his fluid intelligence to solve it. Unlike fluid intelligence, crystallized intelligence suggests that we are able to use our previously acquired knowledge through experience or education. To illustrate, while people are dealing with language skills such as reading comprehension or grammar, they use their crystallized intelligence. As can be seen, these two types of intelligences can be seen different at first; however, they can actually work together. For instance, crystallized intelligence is used to comprehend and follow to understand and follow the instructions in a recipe while cooking something, and fluid intelligence is used when selecting the ingredients to add which suit your taste. Nonetheless, the difference between crystallized intelligence and fluid intelligence is that while the former one increases with age, the latter one decreases. (Horn, Donaldson, \& Engstrom, 1981)

After discussing intelligence and fixed mindset, contrary to fixed mindset, growth mindset is met with different characteristics (Dweck, 2000). Those who have a growth mindset - incremental theorists- support that one's intelligence is fully shaped by self- improvement and determination (Elliott and Dweck, 1988). This is possible because of neuroplasticity - the brain's ability to restructure itself and to form new connections with more repetitive practices, making it stronger in turn. Dweck (2016, p.1) suggests that "In a growth mindset, people believe that their most basic abilities can be developed 
Mind Matters: How is Mindset Correlated with Demographic Variables in Foreign Language Learning?

through dedication and hard work - brains and talent are just the starting point. This view creates a love of learning and a resilience that is essential for great accomplishment. Virtually all great people have had these qualities." To put it differently, the ones who adopt a growth mindset fundamentally believe that talent comes through effort, and their abilities can be further developed when they are dedicated, perseverant and well-trained enough, so intelligence is indeed improvable (Bandura and Dweck, 1985; Dweck and Molden, 2007). The difference between the fixed and growth mindset is summarized by Dweck as follows:

In the fixed mindset, everything is about the outcome. If you fail-or if you're not the bestit's all been wasted. The growth mindset allows people to value what they're doing regardless of the outcome. They're tackling problems, charting new courses, working on important issues. Maybe they haven't found the cure for cancer, but the search was deeply meaningful. (2016, p.30)

Moreover, despite the fact that individuals with a fixed mindset care how they are judged by others, those with a growth mindset focus on their own learning. They welcome feedback as a means to improve rather than ignoring or avoiding it. Furthermore, unlike students with a fixed mindset, if those with a growth mindset make any mistakes, they try to correct it immediately. Failures are just temporary setbacks for growth mindset holders, and they are seen as potential chances for growth-minded students for instructive feedback and thus their mistakes make indeed their learning better (Dweck, 2007). For this reason, they tend to demonstrate more adaptive behaviors and psychological traits such as resilience in response to failure. The success of their peers makes them inspired and gives them some lessons. Taking all these into consideration, learners who are of the opinion that abilities are fixed are less likely to progress better than others who believe that abilities can be improved.

Dweck and Molden (2007) state that there is also one more category where those who do not strongly hold either of these two mindsets-fixed vs growth- compose. Their work indicated that among children and adults, approximately $40 \%$ of them endorse a growth mindset whereas another $40 \%$ adopt fixed mindset. The remaining $20 \%$ is undecided, in other words, they fall into somewhere in the middle of the applied scale points. As opposed to Dweck's (2006) argument, Mercer (2012) asserts that fixed mindset prevails in language learning.

The study of mindsets leads to determining the motivation sources of students and how these motivations can encourage them to fulfill their potential and succeed the best of their ability (Dweck, 2015). Doubtlessly, mindsets shape the actions we take, the lives we lead, and our future world. Studies show that what people believe about their intelligence can substantially affect their achievement, anxiety level and resiliency (Dweck, 2008). Furthermore, research also suggests that holders of a growth mindset are inclined to feel more motivated and to have more academic achievement with higher test scores (Aronson et al., 2002; Castella et al., 2015). Other studies also proved that more specifically, a growth mindset usually leads to better academic outcomes (Castella and Byrne, 2015; Yeager, Johnson, Spitzer, Trzesniewski, Powers and Dweck, 2014).

The relationship between gender and mindset has also been explored in various studies (Kornilova et al., 2009; Macnamara and Rupani, 2017). There are three main views regarding what the findings of these studies suggested: a) Women are more inclined to adopt a fixed mindset than men (Leggett, 1985; Licht and Shapiro, 1982) b) Men are more inclined to have a fixed mindset than women (Spinath, Spinath and Riemann, 2003) c) Women and men do not diverge significantly on their mindsets (Kornilova et al., 2009; Macnamara and Rupani, 2017; Yan et al., 2014). The most common view among the aforementioned ones in the relevant literature is the first one, which suggests that women tend to have a more fixed mindset than men as "Starting in infancy, parents tend to give boys more process praise, an advantage that results in a greater desire for challenge, and a growth mindset, later on." (Dweck and Simmons, 2014, p.12). However, a very recent study conducted by Macnamara and Rupani (2017) contradicted with the existing literature and the common view mentioned above. Their study tested if having a growth mindset predicts learners' achievement. It also examined whether or not women tend to have a more fixed mindset than men. The findings of this study showed that contrary to 
popular belief, fixed mindset was associated with greater academic achievement. Furthermore, another surprising finding was the fact that women either did not diverge from men, or were more likely to endorse a growth mindset, and no indication or discrepancy indication was found regarding the assumption that women hold more fixed mindset than men

\section{METHODOLOGY}

\section{Participants}

The present study was conducted on 203 participants who were enrolled in various programs and were receiving compulsory English prep-class education. Among 203 participants, 100 (49.26\%) of the students are currently studying at Attlım University Preparatory School whereas $103(50.74 \%)$ of the students are currently studying at Gazi University Preparatory School.

In the present study, convenience sampling, a kind of non-probability or non-random sampling method where the participants of study are identified from among the ones who are easily accessible, available at a certain time, or simply willing to participate (Dörnyei, 2007), was preferred to be used. The rationale behind the application of the given sampling technique is because it is quite practical and readily available for participants.

Before applying the scale, as the study has a number of variables, some demographic information about participants was gathered such as their program enrolled, graduated high school type, L2 proficiency level, number of years English is known, and any other languages known along with English and mother tongue. Table 1 shows the details below.

Table 1. Demographic information about the participants

\begin{tabular}{llll}
\hline & & $\mathrm{F}$ & $\%$ \\
\hline \multirow{2}{*}{ Gender } & Female & 90 & 44,3 \\
& Male & 113 & 55,7 \\
\hline \multirow{2}{*}{ The Program Enrolled } & Natural Science & 164 & 80,8 \\
& Social Sciences & 39 & 19,2 \\
\hline & Science High School & 21 & 10,3 \\
& Anatolian High School & 86 & 42,4 \\
& Social Sciences High School & 1 &, 5 \\
& Vocational High School & 10 & 4,9 \\
Type of High School Graduated & Regular High School & 11 & 5,4 \\
& Private High School/College & 57 & 28,1 \\
& Basic High School & 11 & 5,4 \\
& Anatolian Teacher Training High & 6 & 3,0 \\
& School & 154 & 75,9 \\
& Pre-Intermediate & 43 & 21,2 \\
L2 proficiency level & Intermediate & 6 & 3,0 \\
\hline \multirow{2}{*}{ The number of Years English is Known5-10 years } & Upper-Intermediate & 41 & 20,2 \\
& 1-5 years years & 113 & 55,7 \\
\hline Any Other Languages Known Different Yes & 49 & 24,1 \\
from English and Native Tongue & No & 31 & 15,3 \\
\hline
\end{tabular}

\section{Data Collection}

To reach a larger sample group, data were collected at two universities in December, 2017-2018 Fall term. The researcher first started to collect data from Atılım University Preparatory School. Before handing out the scales, she first distributed the Consent Form to the participants. Thanks to this form, 
they were informed about the main objectives of the study. Furthermore, they were also informed that confidentiality and anonymity would be maintained and the results of the study would be anonymously shared with other people or institutions. They were also mentioned that if a participant decided at any time that s/he did not want to participate in this study, s/he could tell the researcher and would withdraw from the study without any reason. The researcher also repeated participants' rights orally. Having read the form, almost all the students accepted to be a part of this research and signed the form. After that, the researcher administered the scales in one week and finished the data collection procedure at Attlim University.

Next, with the help of her colleagues at Gazi University, the researcher started to collect data in the second setting of the study, and the same procedure was applied there. Collecting data from Gazi University took one week as well, and finally the whole data collection procedure was completed in two weeks.

\section{Data Collection Instrument}

In the present study, data were collected using Dweck's Mindset Instrument (2000) which aims to understand how people view their own intelligence and talent. DMI, a 6-point Likert-type Scale, was developed by Dweck (2000) in order to assess how students view their own intelligence and to divide them accordingly into two "mindset" categories: fixed and growth. The reliability of Dweck's Mindset Instrument was found quite high, indicating excellent internal consistency ( $\alpha=0.94$ to 0.98 ) (Dweck, 2000). In line with this, the Cronbach alpha was calculated at .91 in the present study, indicating quite strong internal reliability for DMI.

Originally, Dweck's Mindset Instrument consists of 16 items focusing on both intelligence and talent views of students. However, since all the questions were the same for both intelligence and talent viewpoint items, the researcher did not want to ask them separately and adapted the instrument by combining both intelligence and talent viewpoints in a total of 8 items as follows: 'You have a certain amount of intelligence and talent, and...'. Thus, the number of the items was reduced from 16 to 8 in this study.

As a result, DMI used in this study consists of 8 separate item statements, which students ranked on an agreement scale of 1-6: 1 (strongly agree), 2 (agree), 3 (mostly agree), 4 (mostly disagree), 5 (disagree), and 6 (strongly disagree). By answering the items on the DMI, students revealed what they believe about their own intelligence and success and they were grouped into the mindset they adopt.

There were both fixed and incremental item statements in this instrument. The fixed item statements on the questionnaire consisted of items 1,2, 4, and 6. These items viewed intelligence as fixed and unchangeable. The incremental item statements, which viewed intelligence as changeable, consisted of items 3,5,7, and 8 . The scores selected by students for the incremental item statements would be reversed ( 1 becomes 6,2 becomes 5,3 becomes 4,4 becomes 3, 5 becomes 2, and 6 becomes 1) to ensure that strongly disagreeing with a fixed item statement means strongly agreeing with an incremental item statement. At the end of scoring, students who collected a score between 1 and 3 were considered to view intelligence as something fixed at birth and unable to change, and therefore to have a fixed mindset. Students who gained a score between 4 and 6 were considered to view intelligence as something changeable, and therefore to have a growth mindset. On the other hand, students who gained a score between 3 and 4 were considered as uncertain about intelligence and therefore tended to have both fixed mindset and growth mindset. The items related to growth mindset are negatively and strongly correlated with the fixed mindset items $(-0.69$ and -0.86$)$, which means that if one agrees with the growth mindset items, s/he will disagree with the fixed mindset items. (Dweck, 2000).

By taking participants' language qualification into consideration, this instrument was translated into their native language, Turkish, by the researcher. Therefore, not the original version but the translated version of DMI was administered to the participants. Since it was of great importance to have no difference between both versions, the procedures of translation and back- translation were applied thanks to some native speakers of English and Turkish colleagues. 


\section{Data Analysis}

In the given quantitative correlational study, descriptive and inferential statistical procedures in SPSS Statistics 21.0 were applied to evaluate the collected data. Non-parametric tests were employed as the data was not normally distributed. Before the analysis of the research questions, some preliminary analyses were administered. First, the exploratory factor analysis of DMI was carried out to determine the underlying factor structure of the scale. This step was important since the Turkish version of DMI was translated by the researcher herself for the first time. Next, the reliability analysis of DMI was run to see if the instrument consistently reflects the construct it measures. When it comes to research questions, Chi-Square Test of Independence was run for each research question.

\section{FINDINGS}

\section{Preliminary Analyses}

Exploratory factor analysis, reliability analysis, and principal component analysis were on Dweck's Mindset Instrument (DMI). The results are presented in the following tables:

Table 2. Exploratory factor and the reliability analyses of mindset scale

\begin{tabular}{|c|c|c|c|}
\hline & $\begin{array}{c}\text { Factor } \\
\text { Loading }\end{array}$ & $\begin{array}{l}\text { Item-Total } \\
\text { Correlation }\end{array}$ & $\begin{array}{c}\text { Cronbach's } \\
\text { Alpha }\end{array}$ \\
\hline $\begin{array}{l}\text { 1) You have a certain amount of intelligence, and you really } \\
\text { can't do much to change it. }\end{array}$ & ,750 & ,666 & \multirow{8}{*}{ 910 } \\
\hline $\begin{array}{l}\text { 2) Your intelligence is something about you that you can't } \\
\text { change very much. }\end{array}$ & 811 & ,739 & \\
\hline $\begin{array}{l}\text { 3) No matter who you are, you can significantly change your } \\
\text { intelligence level. }\end{array}$ & ,862 & ,808 & \\
\hline $\begin{array}{l}\text { 4) To be honest, you can't really change how intelligent you } \\
\text { are. }\end{array}$ & ,827 & ,758 & \\
\hline $\begin{array}{l}\text { 5) You can always substantially change how intelligent you } \\
\text { are. }\end{array}$ &, 742 & 659, & \\
\hline $\begin{array}{l}\text { 6) You can learn new things, but you can't really change your } \\
\text { basic intelligence. }\end{array}$ & ,797 & ,720 & \\
\hline $\begin{array}{l}\text { 7) No matter how much intelligence you have, you can } \\
\text { always change it quite a bit. }\end{array}$ & 649, & ,561 & \\
\hline $\begin{array}{l}\text { 8) You can change even your basic intelligence level } \\
\text { considerably. }\end{array}$ & ,821 & ,759 & \\
\hline
\end{tabular}

KMO Value $=0,883$

Bartlett's Test of Sphericity Chi-Square Statistics $=1066,06 \mathrm{Sd}=28$ p=0.000 Total Variance Explained=\% 61,63

Table 3. Principal component analysis of mindset scale

\section{Total Variance Explained}

\begin{tabular}{|c|c|c|c|c|c|c|}
\hline \multicolumn{4}{|c|}{ Initial Eigenvalues } & \multicolumn{3}{|c|}{ Extraction Sums of Squared Loadings } \\
\hline Component & Total & $\%$ of Variance & Cumulative $\%$ & Total & $\%$ of Variance & Cumulative $\%$ \\
\hline 1 & 4,931 & 61,635 & 61,635 & 4,931 & 61,635 & 61,635 \\
\hline 2 & 1,052 & 13,144 & 74,778 & & & \\
\hline 3 &, 583 & 7,282 & 82,060 & & & \\
\hline 4 & ,473 & 5,913 & 87,974 & & & \\
\hline 5 & ,282 & 3,522 & 91,496 & & & \\
\hline 6 & ,246 & 3,069 & 94,565 & & & \\
\hline
\end{tabular}


Mind Matters: How is Mindset Correlated with Demographic Variables in Foreign Language Learning?

\begin{tabular}{lllc|l}
7 & 232 & 2,897 & 97,462 & \\
8 &, 203 & 2,538 & 100,000 & \\
\hline
\end{tabular}

Figure 1. The eigenvalues of the items in mindset scale

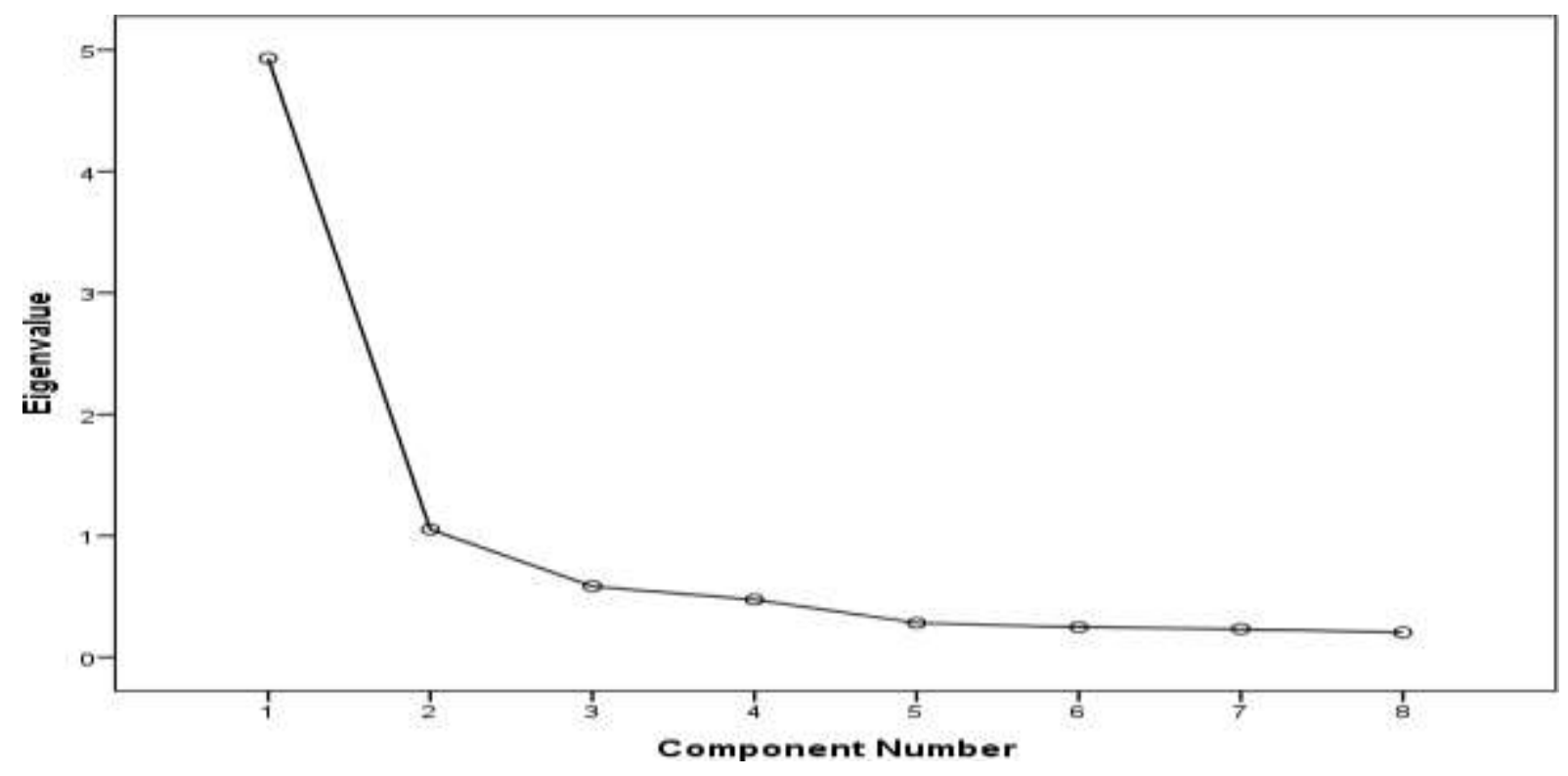

As can be seen from Table 2, the reliability of Dweck's Mindset Instrument was found 0.91 in the current study, suggesting that items on this instrument have excellent internal consistency. According to Dweck, Chiu and Hong (1995), DMI has good internal consistency as well ( $\alpha=.82$ to .97). Therefore, the instrument was found quite valid and reliable to administer to students to collect the data in the current study.

As for the exploratory factor analysis of DMI, 8 items of Dweck's Mindset Instrument were subjected to principal component analysis (PCA). Prior to performing PCA, the suitability of data for factor analysis was first assessed. Kaiser-Meyer-Olkin (KMO) statistics value which determines the sample adequacy was found 0,883 , indicating that the sample was adequate since it was greater than 0.6 (Kaiser 1970, 1974). Test of Sphericity from Bartlett was also found statistically significant ( $<<0.05$ ), meaning that the data was suitable for factor analysis (Field, 2005; Pallant, 2010).

Principal component analysis revealed the existence of two components exceeding 1, explaining $61,6 \%$ and $13,1 \%$ of the variance respectively. However, as can be seen from both scree plot and the table showing the explained total variance, the first eigenvalue $(4,93)$ is almost five times larger than the second eigenvalue $(1,05)$, revealing a clear break after the first component. This was further supported by the total variances explained, with the huge difference between Component 1 contributing $61,6 \%$ and Component 2 contributing 13,1\%, which proves that there was only one dominant factor on the 8 -item scale. When the exploratory factor analysis was repeated forcing this dominant factor, $62 \%$ of total variance was extracted.

All in all, it is seen that factor loadings ranged from 0,649 to 0,862 and all factor loadings were $>0,65$. Along with high factor loadings and high variances, the factorial structure of the 8-item scale had one factor, which was statistically valid. Moreover, item-total correlations are also quite high and vary between 0,561 and 0,808 . 


\section{Main Findings}

Research Question 1: How does the participants' gender correlate with their particular mindset?

For the first research question, whose purpose was to figure out whether or not participants' particular mindset type varies in regard to gender, Chi- Square Test of Independence was applied. Obtained results are summarized in Table 4:

Table 4. Details about the correlation between gender and mindset

\begin{tabular}{llllll}
\hline & & $\begin{array}{l}\text { Gender } \\
\text { Female }\end{array}$ & Male & Total \\
\hline \multirow{3}{*}{ Mindset Type } & \multirow{2}{*}{ Fixed Mindset } & $\mathrm{n}$ & 8 & 29 & 37 \\
& & $\%$ & $8,9 \%$ & $25,7 \%$ & $18,2 \%$ \\
& \multirow{2}{*}{ Undecided } & $\mathrm{n}$ & 15 & 21 & 36 \\
& & $\%$ & $16,7 \%$ & $18,6 \%$ & $17,7 \%$ \\
& \multirow{3}{*}{ Growth Mindset } & $\mathrm{n}$ & 67 & 63 & 130 \\
& & $\%$ & $74,4 \%$ & $55,8 \%$ & $64,0 \%$ \\
\hline \multirow{2}{*}{ Total } & & $\mathrm{n}$ & 90 & 113 & 203 \\
& & $\%$ & $100 \%$ & $100 \%$ & $100,0 \%$ \\
\hline
\end{tabular}

$\underline{\chi^{2}=10,572 \quad \mathrm{p}=0,005}$

As Table 4 illustrates, the findings revealed that participants' particular mindset differed significantly in regard to gender and a significant association was found between mindset and gender $(\chi 2=10.572, p=.005,<0.05)$. It was found out that male participants $(25.7 \%)$ tended to have a more fixed mindset than female participants $(8.9 \%)$ whereas female participants $(74.4 \%)$ were inclined to have a growth mindset more than male participants $(55.8 \%)$.

Research question 2: Is there a statistically significant correlation between participants' program enrolled and their particular mindset?

With regard to the second research question, which tries to explore whether participants' particular mindset type differs or not in regard to the enrolled program, Chi-Square Test of Independence was run. The results are as follows:

Table 5. Details about the correlation between the program enrolled and mindset

\begin{tabular}{llllll}
\hline & & Program Enrolled & & \\
& & & Natural Sciences & $\begin{array}{c}\text { Social } \\
\text { Sciences }\end{array}$ & Total \\
\hline \multirow{2}{*}{ Mindset Type } & \multirow{2}{*}{ Fixed Mindset } & $\mathrm{N}$ & 31 & 6 & 37 \\
& & $\%$ & $18,9 \%$ & $16,2 \%$ & $18,2 \%$ \\
& & $\mathrm{n}$ & 30 & 6 & 36 \\
& & $\%$ & $18,2 \%$ & $15,3 \%$ & $17,7 \%$ \\
& Growth Mindset & $\mathrm{n}$ & 103 & 27 & 130 \\
& & $\%$ & $62,8 \%$ & $69,2 \%$ & $64,0 \%$ \\
\hline
\end{tabular}


Mind Matters: How is Mindset Correlated with Demographic Variables in Foreign Language Learning?

\begin{tabular}{lllll}
\hline \multirow{2}{*}{ Total } & $\mathrm{n}$ & 164 & 39 & 203 \\
& $\%$ & $100 \%$ & $100 \%$ & $100,0 \%$ \\
\hline
\end{tabular}

$\chi 2=0,567 \mathrm{p}=0,753$

As shown in Table 5, the chi-square test of independence statistic value was found to be 0.567 (>0.005) and the p-value was $0.75(>0.05)$, which means that students' particular mindsets did not vary significantly in regard to the enrolled program. Put simply, the findings suggested that no statistically significant correlation existed between learners' mindset and the enrolled program.

Research question 3: What relationship exists between participants' L2 proficiency level and their particular mindset?

To respond to the last research question, seeking to explore the relationship between participants' L2 proficiency level and their particular mindset, Chi-Square Test of Independence was utilized. The results are as follows:

Table 6. Details about the relationship between L2 proficiency level and mindset

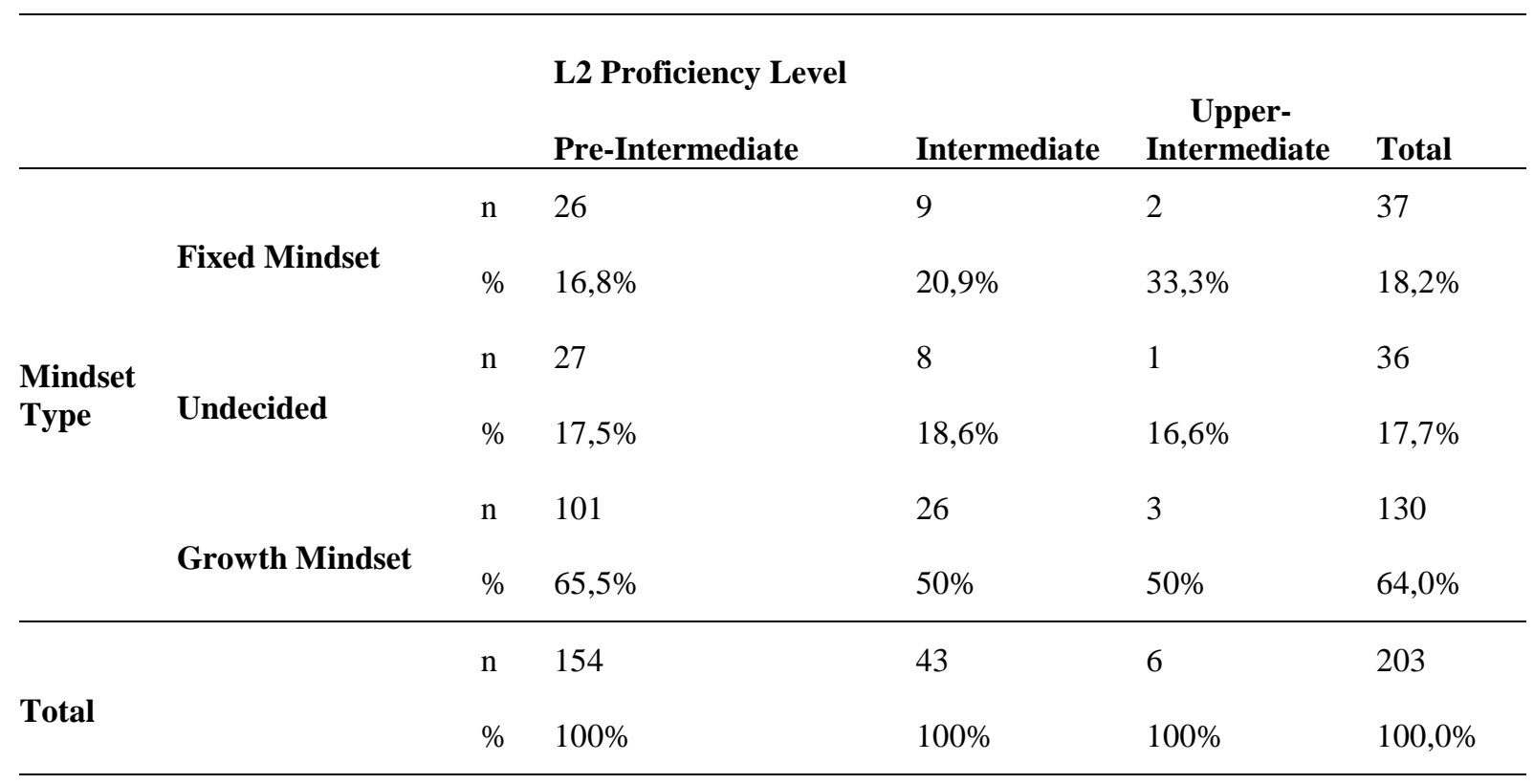

$\chi^{2}=1,430 \mathrm{p}=0,839$

In Table 6 above, the chi-square test of independence statistic value was found to be 1,430 (> $0.005)$ and the $\mathrm{p}$-value is greater than $0.05(\mathrm{p}=.83)$ indicating that students' particular mindsets did not differ significantly in regard to L2 proficiency level. That is to say, Chi Square Test of Independence Analysis results did not assert any statistically significant association between learners' mindset and their L2 proficiency level, meaning that the mindset they adopt did not differ significantly with regard to their L2 proficiency level.

\section{DISCUSSION \& CONCLUSION}

This quantitative correlational study addressed the research gap in the relationship between mindset and personal variables. Following an analysis of the collected data, the researcher, first of all, confirmed that mindset adopted by female and male learners significantly differs from each other. It appears that male learners are more inclined to have a more fixed mindset than females. However, it was found out that no relationship existed between students' enrolled program and mindset. Likewise, 
İrem Altunel

it was concluded that the type of mindset students adopted is not consistently associated with their L2 proficiency level.

When the results obtained from the current study are evaluated, it was revealed that there was a statistically significant relationship between gender and mindset in that females tended to adopt growth mindset more than males whereas males had more of a fixed mindset than females. This result is in line with Spinath, Spinath and Riemann's (2003) and Macnamara and Rupani's (2017, Study 1) studies finding out that females considered intelligence (mindset) to be less stable than males did. The results of this study, on the other hand, conflict with some studies claiming that either females or males do not differ on mindsets (Kornilova et al., 2009; Macnamara and Rupani, 2017, (Study 2 \& 3) and that female learners tended to have a fixed mindset more than their male counterparts (Dweck, 2008). Yet, it is crucial to note that not all the aforementioned studies regarding gender and mindset were conducted on EFL learners unlike the current study. For instance, Heyman et al. (2001) carried out their study on engineering students while Dweck (2008) followed 373 junior high school students to investigate whether or not mindset predicts math and science achievement. At this point, it is essential to emphasize that attitudes towards learning is much more dominant for girls while learning a foreign language (Burstall, 1975). Furthermore, it has been seen that females are more motivated in foreign language learning than males (Dörnyei, Csizer and Nemeth, 2006) and their sources of motivation generally differ. For example, to learn a new foreign language, female learners often find more integrative reasons which are proven to be strong impetus in language learning such as learning the culture of the country where the target language is spoken. Yet, male learners choose learning a foreign language due to the fact that they are more instrumentally motivated and they view a foreign language as "a subject to fill in the timetable" (Powell and Littlewood, 1983, p.36) or getting a high- ranking job with a good salary (Gardner and Lambert, 1972). Taking this fact into consideration, the results of this study, which indicate that females tend to adopt growth mindset more than males, can relate to the perception and motivation underlying their desire to learn a foreign language, and thus can be explained that since girls have more integrated motivation towards language learning than boys, they may as well be more inclined to endorse growth mindset.

When the mindset literature is reviewed, it is observed that although much has been researched on mindset, to the best of researcher's knowledge, there have been no known studies specifically investigating the relationship between mindset and the program enrolled (categorized as natural sciences vs. social sciences). With this in mind, the findings of the current study have tried to eliminate the gap in this issue. The results of the study revealed that students' particular mindsets did not vary significantly in regard to the program enrolled. Put it differently, whether students studied natural sciences (e.g. engineering, medicine) or social sciences (e.g. psychology, business administration) did not determine significantly the mindset (fixed vs growth) they adopted. The reason behind this finding would be the fact that social-psychological factors such as motivation, attitude, aptitude or learner beliefs may play a more crucial role in shaping one's particular mindset type.

Reviewing the existing literature regarding the relationship between mindset and L2 proficiency, although a large body of research was carried out in order to figure out the connection between L2 proficiency and different variables such as language learning strategy (Roohani et al., 2013) and motivation (Gardner et al., 1977), no specific study investigating the relationship between mindset and L2 proficiency was found. As Mercer and Ryan (2009) also suggest, further research is needed to be carried out among students with different language proficiency levels to examine the correlation, if any, between their mindset and L2 proficiency level. Therefore, in an effort to eliminate the gap, this study tried to determine the relationship between two variables, and found out that no significant relationship existed between mindset and L2 proficiency level. That is to say, no matter how proficient a learner is in the target language, his/her proficiency level is not a predictor of the type of mindset adopted. It is wrong to consider upper-intermediate level students as having a growth mindset or elementary level students as having a fixed mindset since it is not proven to be true in the present study. This result might have occurred because how one views intelligence, in other words, his/her mindset may start to shape during childhood and continue to improve throughout adulthood, so adopting a fixed or growth mindset may require a long process profoundly affected by beliefs, choices and life 
Mind Matters: How is Mindset Correlated with Demographic Variables in Foreign Language Learning?

experiences. Therefore, it is not surprising that no significant relationship was found between mindset and L2 proficiency.

The present study suggests that some future efforts could be invested in combining quantitative data with the qualitative data, e.g. making interviews with some students as well as administering the related scales, in order to have a better in-depth understanding about the answers of the research questions. Secondly, the current study was a descriptive correlational research indicating only the correlations between various variables, not causations. Thus, more causal studies investigating the cause and effect relations between these variables may contribute to the findings and lead researchers to reach more causal conclusions. Next, in addition to the cross-sectional studies, longitudinal studies should be carried out further in order to have a deeper understanding of the relationship among mindset, foreign language anxiety, and certain related variables.

\section{REFERENCES}

Ablard, K.E., \& Mills, C.J. (1996). Implicit theories of intelligence and self- perceptions of academically talented adolescents and children. Journal of Youth and Adolescents, 25, 137-148.

Altunel, İ. (2019). An Investigation into the Relationship between Mindset and Foreign Language Anxiety. (Master's thesis, Eğitim Bilimleri Enstitüsü).

Aronson, J., Fried, C. B., \& Good, C. (2002). Reducing the effects of stereotype threat on African American college students by shaping theories of intelligence. Journal of Experimental Social Psychology, 38(2), 113-125.

Bandura, M., \& Dweck, C.S. (1985). The relationship of conceptions of intelligence and achievement goals to achievement-related cognition, affect, and behavior. Unpublished manuscript, Harvard University.

Burstall, C. (1975). Factors affecting foreign language learning: a consideration of some relevant research findings, in Language Teaching and Linguistics Abstracts, 8: 105-25.

Castella, K., \& Byrne, D. (2015). My intelligence may be more malleable than yours: the revised implicit theories of intelligence (self-theory) scale is a better predictor of achievement, motivation, and student disengagement. European Journal of Psychology of Education, 30(3), 245-267.

Cattell, R. B. (1963). Theory of fluid and crystallized intelligence: A critical experiment. Journal of Educational Psychology, 54(1), 1.

Dörnyei, Z., Csizer, K., \& Nemeth, N. (2006) Motivation, language attitudes, and globalization: A Hungarian perspective. Multilingual Matters.

Dörnyei, Z. (2007). Research methods in applied linguistics. New York: Oxford University Press.

Dweck, C.S., \& Leggett, E.L. (1988). A social cognitive approach to motivation and personality. Psychological Review, 95(2), 256-273.

Dweck, C.S., Chiu, C., \& Hong, Y. (1995). Implicit theories and their role in judgments and reactions: a world from two perspectives. Psychological Inquiry, 6, 267-285.

Dweck, C.S. (2000). Self-theories: Their role in motivation, personality and development. Philadelphia: Taylor and Francis. Psychology Press.

Dweck, C.S. \& Molden, D. (2007). Self-theories: Their impact on competence motivation and acquisition. In A. Eliot and C. Dweck (Eds.), Handbook of Competence and Motivation (pp. 122-140). London: The Guilford Press.

Dweck, C. S. (2008). Mindsets and math/science achievement. New York: Carnegie Corporation of New York.

Dweck, C., \& Simmons, R. (2014). Why do women fail? Retrieved from 


\section{http://www.cnn.com/2014/07/29/opinion/dweck-simmons-girls-confidence-failure/>}

Dweck, C. (2015). Carol Dweck Revisits the 'Growth Mindset'. Education Week. Retrieved from: https://www.edweek.org/ew/articles/2015/09/23/carol-dweck-revisits-the-growth-mindset.html

Dweck, C. (2016). Mindset: The new psychology of success (Updated Edition). New York: Ballantine Books.

Elliott, E. S., \& Dweck, C. S. (1988). Goals: An approach to motivation and achievement. Journal of Personality and Social Psychology, 54, 5-12.

Elliot, A.J. \& Dweck, C.S. (2005). Competence and motivation: Competence as the core of achievement motivation. In A. J. Elliot ve C. S. Dweck (Ed.), Handbook of Competence and Motivation (pp. 3-12). New York, USA: The Guilford Press.

Field, A. (2005). Discovering statistics using SPSS (2nd ed.). London: Sage.

Gardner, R. C, \& Lambert, W. E. (1972). Attitudes and motivation in L2 learning. Rowley, MA: Newbury House.

Gardner, R.C., Smythe, P.C., \& Brunet, G.R. (1977). Intensive second language study: Effects on attitudes, motivation, and French achievement. Language Learning, 27, 243-261.

Heyman, G. D., Martyna, B., \& Bhatia, S. (2001). Gender and achievement-related beliefs among engineering students. Journal of Women and Minorities in Science and Engineering, 8, 41-52.

Horn, J. L., Donaldson, G., \& Engstrom, R. (1981). Apprehension, memory, and fluid intelligence decline in adulthood. Research on Aging, 3(1), 33-84.

Kaiser, H. (1970). A second generation Little Jiffy. Psychometrika, 35, 401-15.

Kaiser, H. (1974). An index of factorial simplicity. Psychometrika, 39, 31-6.

Kornilova, T. V., Kornilov, S. A., \& Chumakova, M. A. (2009). Subjective evaluations of intelligence and academic self-concept predict academic achievement: Evidence from a selective student population. Learning and Individual Differences, 19(4), 596-608.

Leggett, E. L. (1985). Children's entity and incremental theories of intelligence: Relationships to achievement behavior. In annual meeting of the Eastern Psychological Association, Boston.

Licht, B. G., \& Shapiro, S. H. (1982). Sex differences in attributions among high achievers. In meeting of the American Psychological Association, Washington, DC.

Macnamara, B. N., \& Rupani, N. S. (2017). The relationship between intelligence and mindset. Intelligence, 64, 52-59.

Mercer, S., \& Ryan, S. (2009). A mindset for EFL: Learners' beliefs about the role of natural talent. ELT journal, 64(4), 436-444.

Mercer, S. (2012). Dispelling the myth of the natural-born linguist. ELT Journal, 62 (1), 22-29.

Mueller, C. M., \& Dweck, C. S. (1998). Praise for intelligence can undermine children's motivation and performance. Journal of Personality and Social Psychology, 75(1), 33-52.

Nussbaum, A. D., \& Dweck, C. S. (2008). Defensiveness vs. remediation: Self- theories and modes of self-esteem maintenance. Personality and Social Psychology Bulletin, 34, 599 - 612.

Pallant, J., (2010). SPSS survival manual: A step by step guide to data analysis using the SPSS program. 4th Edition, McGraw Hill, New York.

Powell R.C. and Littlewood, P. (1983) Why choose French? Boys' and girls' attitudes at the option stage. In The British Journal of Language Teaching, 21, 1: 36-9.

Roohani, A., \& Rabiei, S. (2013). Exploring Language Learning Strategy Use: The Role of Multiple 
Mind Matters: How is Mindset Correlated with Demographic Variables in Foreign Language Learning?

Intelligences, L2 Proficiency and Gender. Journal of Teaching Language Skills, 32(3), 41-64.

Spinath, B., Spinath, F. M., Riemann, R., \& Angleitner, A. (2003). Implicit theories about personality and intelligence and their relationship to actual personality and intelligence. Personality and Individual Differences, 35, 939-951. http://dx.doi.org/10. 1016/S0191-8869(02)00310-0.

Yeager, D. S., Johnson, R., Spitzer, B. J., Trzesniewski, K. H., Powers, J., \& Dweck, C. S. (2014). The far-reaching effects of believing people can change: Implicit theories of personality shape stress, health, and achievement during adolescence. Journal of Personality and Social Psychology, $106(6), 867$. 